\title{
Eğirdir Orman Fidanlığı’nda diken ardıcı (Juniperus oxycedrus L. subsp. oxycedrus) fidan yetiştirme sıklığının fidan morfolojisine etkileri
}

Esra ALIM (Orcid: 0000-0003-2433-8834) ${ }^{1^{*}}$, Ali KAVGACI (Orcid: 0000-0002-4549-3668) ${ }^{2}$

\author{
${ }^{1}$ Batı Akdeniz Tarımsal Araştırma Enstitüsü Müdürlüğü, ANTALYA \\ ${ }^{2}$ Batı Akdeniz Ormancılık Araştırma Enstitüsü Müdürlüğü, ANTALYA \\ "Sorumlu yazar/Corresponding author: alimesra@hotmail.com, Geliş tarihi/Received: 26.04.2017, Kabul tarihi/Accepted: 16.06.2017
}

$\ddot{O} \mathbf{z}$

Bu çalışmada, farklı yetiştirme sıklıklarının diken ardıcı (Juniperus oxycedrus L. subsp. oxycedrus)'nın (1+0) çıplak köklü fidanlarının morfolojik özellikleri üzerindeki etkilerini ortaya koymak amaçlanmıştır. Araştırma Eğirdir Orman Fidanlığında kurulan deneme alanlarında yürütülmüştür. Denemede; $1.5 \mathrm{~cm}, 3 \mathrm{~cm}, 6 \mathrm{~cm}$ ve $9 \mathrm{~cm}$ mesafe olacak şekilde kontrol dâhil 5 farklı yetiştirme sıklığı uygulanmıştır. Araştırma sonuçlarına göre diken ardıcı fidanlarının morfolojik özellikleri (kök boğazı çapı, yan kök sayısı, gürbüzlük indisi, kalite indisi, fidan, gövde ve kök taze ağırlıkları ile fidan, gövde ve kök kuru ağırlıkları) üzerine yetiştirme sıklığının önemli etkilerinin olduğu belirlenmiştir. Ekim yastıklarında yetiştirme sıklığı azaldıkça daha kalın çaplı, gövde taze ve kuru ağırlığı daha fazla ve daha çok yan kök sayısına sahip olan fidanlar elde edilmiştir. Çalışmada, elde edilen fidanlar arasında en yüksek kök boğazı çapı ve yan kök sayısı kontrol dışındaki ekim sıklıklarından elde edilen fidanlarda olduğu tespit edilmiştir. Fidan ağırlıkları bakımından ise en iyi sonucu $3 \mathrm{~cm}$ ekim sıklığ 1 verirken, en düşük sonuç kontrol fidanlarında meydana gelmiştir. Eğirdir Orman Fidanlığı koşullarında $3 \mathrm{~cm}$ ekim sıklığının uygulanmasının kaliteli diken ardıcı fidan üretimi için yeterli olacağı düşünülmektedir.

Anahtar Kelimeler: Diken ardıcı, fidan kalitesi, fidan morfolojisi, yetiştirme sıklığı.

\section{The effects of cultivation density on morphological characteristics of prickly juniper (Juniperus oxycedrus L. subsp. oxycedrus) seedlings in Eğirdir Forest Nursery}

\begin{abstract}
In this work, it was aimed to clarify the effects of different cultivation density on the morphological characteristics of prickly juniper (Juniperus oxycedrus L. subsp. oxycedrus) seedlings. The study was carried out at the sowing beds in the Eğirdir Forest Nursey. Five different cultivation densities were applied in the study. These are $1.5 \mathrm{~cm}, 3 \mathrm{~cm}$, $6, \mathrm{~cm}, 9 \mathrm{~cm}$ distances and the control plots without any application. In the study, it was observed that the different cultivation density effected the morphological characteristics of prickly juniper seedlings in many ways such as root collar diameter, number of lateral roots, index of robustness, quality index, fresh and dry weights of seedling's stem and root. With the decrease of cultivation density in the sowing beds, root collar diameter, fresh and dry weights of stem and the number of lateral roots increased. Except the control plots, all other plots with different cultivation densities showed high root collar diameter and number of lateral roots. In terms of the seedling weight, the best results were obtained from the $3 \mathrm{~cm}$ cultivation density plots whereas the worst was at control plots. In conclusion, for the propagation of prickly juniper seedlings in Eğirdir Forest Nursery, $3 \mathrm{~cm}$ cultivation density can be proposed.
\end{abstract}

Keywords: Prickly Juniper, seedling quality, seedling morphology, cultivation density.

To cite this article (Atıf): ALIM, E. (0000-0003-2433-8834), KAVGACI A., 2017. Eğirdir Orman Fidanlığı'nda diken ardıcı (Juniperus oxycedrus L. subsp. oxycedrus) fidan yetiştirme sıklığının fidan morfolojisine etkileri, Orman Genel Müdürlügü Ormancılık Araştırma Dergisi, 1(4):01-11 DOI: https://doi.org/10.17568/ogmoad.309242

\section{Giriş}

Ardıçlar, 958.423 ha'lık yayılışları ile ülkemizin önemli orman ağacı türlerindendir (Anonim 2015). Özellikle Akdeniz bölgesinde gerek saha ve gerekse servet olarak önemli yer tutmaktadirlar (Eler, 1988). Batı Akdeniz Bölgesi'nde yayılış gösteren önemli ardıç türleri; kokulu ardıç (Juniperus foe- tidissima Willd.), boylu ardıç (Juniperus excelsa Bieb.), diken ardicı (Juniperus oxycedrus L.) ve finike ardıc1 (Juniperus phoenicia L.)'dır.

Ardıç türleri ekolojik salınımları geniş türlerdir. Bunun en önemli göstergeleri bu türlerin alçak ve yüksek sıcaklık ekstremlerine diğer türlere oranla daha dayanıklı olmaları, kötü yetişme ortamların- 
da yayılış göstermeleri ve yaygın kök sistemleridir (Pamay, 1955; Gülcü ve Gültekin, 2005a). Nitekim bu özelliklerinden dolayı erozyon önleme çalışmalarında bu türler yoğun olarak kullanılmaktadır.

Ardıç, odununun çok dayanıklı, kolay işlenebilen, ince tekstürlü ve güzel kokulu olmasından dolayı geniş bir kullanım alanına sahiptir (Yaltırık, 1988). Ardıçların tıp ve kozmetik alanında da yoğun kullanımı bulunmaktadır. Cinsin bazı türleri yeşil kuşak ağaçlandırmaları ile rüzgar ve kar perdesi oluşturmada da kullanılmaktadır (Ürgenç, 1998; Gültekin ve Gültekin, 2003). Estetik görünümlerinden dolayı ardıçlar park-bahçe planlamada da yoğun kullanıma sahiptir (Ürgenç, 1998; Gültekin ve Gültekin, 2003). Ardıçlar sahip oldukları form sayesinde yaban hayatı için çok uygun barınma ve beslenme ortamı yaratmaktadırlar (Gültekin, 2007; Pamay, 1955).

Akdeniz bölgesinde saf ve karışık olarak yayılış gösteren ardıç ormanları özellikle uzun yıllardır devam eden yoğun otlatma nedeniyle nitelik ve nicelik yününden istenilen seviyede değildir. (Gültekin ve Öztürk, 2002). Öte yandan cinsin tohumlarındaki çimlenme engeli sorununun son yıllara kadar çözülememiş olması bu alanların verimli hale dönüştürülmesinde önemli bir engel olmuştur (Eler ve Keskin, 1990, Gülcü ve ark., 2005). Bununla birlikte, yaşlı ardıç ağaçlarında gövde çürüklüğü ve özellikle 80 yaşından sonra öz çürüklüğü başlamaktadır (Eler ve Keskin, 1990). Bu durum yaşlı ardıç ormanlarının gençleştirilmesi ya da genç ormanların da kuruluşlarının iyileştirilmesinin önemini ortaya koymaktadır.

Ardıç ormanlarının bozuk kuruluşta olması büyük bir artım kaybına neden olmakta, bu ise ülke ekonomisi açısından bir kayıp anlamına gelmektedir. Bozuk kuruluştaki ardıç sahalarının rehabilite edilmesi ve gerektiğinde gençleştirilerek verimli ormanlar haline dönüştürülmesi ülke ekonomisine katkı sağlama açısından önemlidir (Eler ve Çetin, 2006). Bu kapsamda son yıllarda fidanlıklarda kitlesel olarak gerçekleştirilen ardıç fidanı üretimi önemlidir.

Eğirdir Orman Fidanlığı'nda 2000'li yılların başlarında başlatılan çalışmalarla birlikte ardıçta dolu tohumun elde edilmesi ve tohumda var olan çimlenme engelinin ortadan kaldırılması yönünde önemli başarılar elde edilmiştir (Gültekin ve ark. 2003; Gülcü ve Gültekin, 2005a; Gültekin, 2007). Nitekim bu çalışmaların sonucunda, ülke ölçeğinde kitlesel üretimlere başlanmış ve elde edilen fidanlarla ağaçlandırma ve rehabilitasyon çalışmaları- na ağırlık verilmiştir. Bu çalışmalar çoğunlukla başarılı olmakla birlikte, örneğin diken ardıcında (Juniperus oxycedrus) 1+0 çıplak köklü fidanlarla yapılan dikimlerde başarı oranı düşük kalmaktadır (Gültekin, 2007). Bu ise gerek fidanlık tekniği, gerekse doğru fidan materyali seçiminin önemini ortaya koymaktadır.

Ağaçlandırma başarısı üzerinde etkili olan önemli faktörlerden biri fidan kalitesi olup, fidan kalitesini de uygun yetiştirme sıklığı ile artırmak mümkündür (Cengiz ve Şahin, 2002). Yetiştirme sıklığ1 fidanların çapı, boyu ve fizyolojik faaliyetleri üzerine doğrudan etkilidir (Tolay, 1987). Seyrek bir şekilde yetiştirme yapmanın ekonomik bazı kayıpları olabileceği gibi (Saatçioğlu, 1976), sık yetiştirmede de fidanların zayıf kalması gibi bir durumla karşılaşmak mümkündür. Dolayısıyla, uygun yetiştirme sıklığının tespitine yönelik çalışmalar önemli olup, son yıllarda ağaçlandırma çalışmalarında yoğun olarak kullanılmaya başlanan diken ardıcında da fidan kalitesini artırmaya yönelik olarak uygun yetiştirme sıklığının belirlenmesinin önemli olduğu düşünülmektedir.

Diken ardıçları 10-15 m’ye kadar boylanabilen ağaçlar olabildikleri gibi çalı formunda da yayılışları bulunmaktadır (Akkemik ve Yaltırık, 2011). Ülkemizde oldukça geniş bir coğrafyada çok değişik yükselti basamaklarında yayılış göstermektedir. Saf meşcereler kurmayan diken ardıcı, gölgeye dayanıklı olması nedeniyle asli orman ağacı meşcerelerinin alt tabakasında yer alabilmektedir (Gültekin, 2007). Tür, Akdeniz sert yapraklı orman ve çalı vejetasyonunun da önemli bitkilerinden biridir. Diken ardıcı, çoğunlukla güneşli bakılarda, fizyolojik derinliği az ve alkali topraklar üzerinde yer almaktadır (Gültekin, 2007).

Diken ardıcının fidanlık ve ağaçlandırma tekniğiyle ilgili yeterli bilgi bulunmamaktadır. Bu doğrultuda elde edilecek bilgiler tür ile yapılacak ağaçlandırma çalışmalarının başarısını artırma açısından önemlidir. Son yıllarda değişik amaçlarla ağaçlandırma çalışmalarında kullanılmaya başlanan diken ardıcı fidanları ile yapılacak ağaçlandırma çalışmalarının başarısının arttırılmasında da yeterli kalitede ve miktarda fidana ihtiyaç vardır. Bu kapsamda gerçekleştirmiş olduğumuz araştırma çalışmasında diken ardıcında kaliteli fidan üretimine yönelik olarak uygun yetiştirme sıklığının tespit edilmesi amaçlanmıştır. 


\section{Materyal ve Yöntem}

\subsection{Materyal}

Çalışma Isparta ili Eğirdir Orman Fidanlığı'nda gerçekleştirilmiştir. Eğirdir Orman Fidanlığı Akdeniz iklimi geçiş bölgesinde yer alan yar1-karasal iklime sahiptir ve rakımı 926 m'dir. Fidanlığın yıllık ortalama sicaklığ $13,8{ }^{\circ} \mathrm{C}$, yıllık ortalama yağ1Ş1 ise $877,3 \mathrm{~mm}$ 'dir.

Çalışma yapılan ekim parselinden 2015 yılında alınan toprak örnekleri, Batı Akdeniz Ormancılık Araştırma Enstitüsü'nün Toprak Laboratuvarında analiz edilmiştir. Toprağın \%55,43'ü kum, $\% 31,30$ 'u toz ve \%13,27'si kildir ve kumlu balçık tekstüründedir. Toprağın pH's1 8,31, organik madde içeriği ise \%1,04 olarak belirlenmiştir.

Fidan üretimi için Güneyce orjinli diken ardıcı tohumları kullanılmıştır. Tohumların 1000 tane ağırlığı 26,8 g'dır. Aralık ve Ocak aylarında olgun hale gelen kozalaklar Eğirdir Orman Fidanlığı tarafından toplanmıştır. Toplanan kozalaklar önce yaş iken çiğnenmiş, sonra suda yıkanmış ve temizlenmiştir. Kozalaklardan çıkan tohumlar 3 gün meşe külüne yatırılarak günde 3 defa karıştırılmış ve dışındaki reçinelerin kaybolması sağlanarak su ile yıkanmıştır. Yıkanan tohumlar \%5'lik $\mathrm{NaCl}$ çözeltisinde 3 gün bekletilmiş ve nemli olarak +4 ${ }^{0} \mathrm{C}$ soğuk hava deposuna konulmuştur. Diken ardıcı tohumları yastıklara Eylül ayında ekilerek üzerine telis örtülmüştür. Şubat ayında çimlenmeye başlayan tohumların üzerine tünel yapılmış ve don tehlikesi geçtikten sonra Mayıs ayında ardıçların üzerindeki tüneller kaldırılmıştır.

\subsection{Yöntem}

Çalışma kapsamında oluşturulan deneme deseni tesadüf parselleri deneme deseni şeklinde, dört yinelemeli olarak kurulmuştur. Oluşturulan bu desene tohumların ekimi 24 Eylül 2014 tarihinde fidanlığın rutin işlemi şeklinde gerçekleştirilmiştir ( $\mathrm{m}^{2}$ ye 40 gr tohum ve çizgi ekimi yöntemi). Ekim yastığında çimlenmeler gerçekleştikten sonra (Mayıs, 2015) Tablo 1'de belirtilen farklı yetiştirme sıklıklarına uygun şekilde seyreltmeler yapılmıştır (kontrol (sık ekim), 1,5 cm, $3 \mathrm{~cm}, 6 \mathrm{~cm}$ ve $9 \mathrm{~cm}$ ). Seyreltme esnasında işlem parselleri arasında 50 cm'lik mesafe bırakılarak tecrit zonu oluşturulmuştur. Fidanlık yastıklarında ekimler 7 sira halinde olup, ekim yastıklarının eni $120 \mathrm{~cm}$ ve çizgiler aras1 uzaklık $17 \mathrm{~cm}$ olacak şekilde fidanlıkta uygulanmakta olan ölçülere uyulmuştur. Deneme alanında yapılan bakım işleri (ilaçlama, ot alma, sulama vb.) zaman ve şekil olarak, fidanlıkta uygulanan rutin takvime bağlı olarak gerçekleştirilmiştir.

Vejetasyon dönemi sonunda 1 Aralık 2015 tarihi itibariyle her işlem parselinden 25 adet fidan bel küreği kullanılarak kökleri zedelenmeden sökülmüş ve polietilen torbalara konularak Batı Akdeniz Ormancılık Araştırma Enstitüsü Müdürlüğü Laboratuvarına getirilmiştir. Bu fidanlar yastık ortasında kalan çizgi üzerinden tesadüfi olarak seçilmiştir.

Fidanlar üzerindeki ölçümlere başlamadan önce fidanlar köklerine zarar vermeden temizlenmiş ve ölçüme hazır hale getirilmiştir. Her bir yetiştirme sıklığından her tekerrürde $25^{\prime}$ 'er fidan olacak şekilde 4 tekerrürlü olmak üzere (5 işlem x 4 tekerrür x 25 fidan) toplamda 500 fidan üzerinde ölçümler yapılmıştır. Fidanlarda ölçülen bazı morfolojik özellikler ile ölçüm sonuçlarından hesaplanan değerler aşağıda belirtildiği şekildedir:

Fidan Boyu (cm) (FB): Fidan kök boğazı ile tepe sürgününe ait uç tomurcuğun ucu arasındaki mesafedir.

Kök Boğazı Çapı (mm) (KBÇ): Kök sisteminin en üstünde çoğu kez hafif kabarıklık ve renk farkı ile beliren yere ait çaptır.

Yan Kök Sayısı (adet) (YKS): Kök sisteminde $5 \mathrm{~cm}$ den uzun olan yan köklerin sayısıdır.

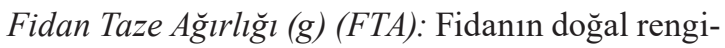
ni ve canlılığını koruduğu sürece olan ağırlığıdır.

Gövde Taze A $\breve{g} ı r l ı \breve{g l}$ (g) (GTA): Fidanın toprak üstü organlarının doğal rengini ve canlılığını koruduğu sürece olan ağırlığıdır.

Kök Taze A $\breve{g} ı r l ı \breve{g l}$ (g) (KTA): Kök boğazı çapı hizasından kesilerek gövdeden ayrılan kök kısmının doğal rengini ve canlılığını koruduğu sürece olan ağırlığıdır.

Fidan Kuru Ağırlığ $(g)$ (FKA): Fidanın firın kurusu $\left(105{ }^{\circ} \mathrm{C}\right.$ 'de 24 saat) ağırlığgdır.

Gövde Kuru Ă̆ırlı̆̆l (g) (GKA): Fidanın toprak üstü organlarının firın kurusu $\left(105{ }^{\circ} \mathrm{C}\right.$ 'de 24 saat) ağırlığıdır.

Kök Kuru A ğırlı̆̆ı (g) (KKA): Kök boğazı çapı hizasından kesilerek gövdeden ayrılan kök kısmının fırın kurusu ( $105^{\circ} \mathrm{C}$ 'de 24 saat) ağırlığıdır.

Katlılık (K): Gövde Kuru Ağırlığı (GKA)/ Kök Kuru Ağırlığı (KKA)

Gürbüzlük Indisi (GI): Fidan Boyu (mm) (FB) / Kök Boğazı Çapı (cm) (KBÇ) 
Kuru Kök Yüzdesi (\%) (KK): Kök Kuru Ağırlı̆̆1 (KKA) / Fidan Kuru Ağırlığı (FKA)

Kalite İndeksi (Kİ): Fidan Kuru Ağırlığı(FKA)/ (Gürbüzlük indisi(GI) + Katlılık (K))

Fidanların ölçümlerinden elde edilen verilerinin değerlendirilmesinde SPSS programı kullanılarak varyans analizi uygulanmıştır, İşlemler arasında farklılığın önemli çıkması durumunda ise farklılığ1 oluşturan grupların tespitinde Duncan çoklu karşılaştırma testi uygulanmıştır (Kalıpsız,1981).

\section{Bulgular}

Diken ardıcı fidanlarında uygulanan farklı yetiştirme siklıklarının (kontrol, 1,5 cm, $3 \mathrm{~cm}, 6 \mathrm{~cm}$ ve $9 \mathrm{~cm}$ ) fidanların morfolojik özellikleri üzerindeki

Tablo 1. Diken ardıcı fidanlarının yetiştirme sıklığı

Table 1. Cultivation density of prickly juniper seedlings

\begin{tabular}{cc}
\hline $\begin{array}{c}\text { Uygulanan Aralık-Mesafe } \\
(\mathrm{cm} \mathrm{x} \mathrm{cm})\end{array}$ & $\begin{array}{c}\text { Ortalama Siklık Derecesi } \\
\left(\text { Fidan } / \mathrm{m}^{2}\right)\end{array}$ \\
\hline Kontrol & 600 \\
$17 \times 1,5$ & 385 \\
$17 \times 3$ & 189 \\
$17 \times 6$ & 91 \\
$17 \times 9$ & 63 \\
\hline
\end{tabular}

etkisini belirlemek amacı ile yapılan varyans analizinde, kök boğazı çapı (mm), yan kök sayısı (adet), gürbüzlük indisi, Dickson kalite indeksi, fidan, gövde ve kök taze ağırlıkları (g) ile fidan, gövde ve kök kuru ağırlıkları (g) üzerine istatiksel anlamda önemli etkileri olduğu tespit edilmiştir $(\mathrm{p} \leq 0,05)$ (Tablo 2).

Diken ardıcı fidanlarında uygulanan farklı yetiştirme sıklığının varyans analizi sonucunda ortaya çıkan farklılıkları, uygulamalar açısından belirlemek amaciyla yapılan Duncan analiz sonuçları Tablo 3'te sunulmuştur.

3.1. Farklı yetiştirme sıklığının diken ardıcı fidanlarının boy (FB) gelişimi üzerine etkisi

Yapılan varyans analizi sonucunda farklı yetiştirme sıklığında yetişen diken ardıcı fidanlarında boy gelişimi bakımından istatistiksel anlamda fark olmadığ1 görülmüştür (Tablo 2). Fidanlarda yap1lan ölçümlere göre, en yüksek fidan boyu $1,5 \mathrm{~cm}$ $(13,24 \mathrm{~cm})$, en düşük ise kontrol $(11,49 \mathrm{~cm})$ yetiştirme sıklığında elde edilmiştir.

\subsection{Farklı yetiştirme sıklığının diken ardıcı fidanlarının kök boğazı çapı (KBÇ) gelişimi üzerine etkisi}

Araştırma sonuçlarına göre, farklı yetiştirme sıklığında yetişen diken ardıcı fidanlarının kök boğazı çapı bakımından istatistiksel olarak $(p \leq 0,05)$ farklı olduğu belirlenmiştir. Yapılan Duncan çoklu karşılaştırma analizine göre, en yüksek kök boğazı çap1 aynı istatistik gruba dahil olan, sırası ile 1,5 cm, 3 $\mathrm{cm}, 6 \mathrm{~cm}$ ve $9 \mathrm{~cm}$ siklıkta yetişen fidanlarda $(2,79$ $\mathrm{mm}, 2,91 \mathrm{~mm}, 2,94 \mathrm{~mm}$ ve 3,06 mm) meydana gel- miştir. En düşük kök boğazı çapı ise kontrol uygulamasında $(1,93 \mathrm{~mm})$ elde edilmiştir.

\subsection{Farklı yetiştirme sıklığının diken ardıcı fidanlarının yan kök sayısı (YKS) üzerine etkisi}

Farklı yetiştirme sıklı̆̆ında yetişen diken ardıcı fidanlarının 5 cm'yi geçen yan kök sayısı bakımından istatistiksel olarak $(\mathrm{p} \leq 0,05)$ farklı olduğu belirlenmiştir. Yapılan Duncan çoklu karşılaştırma analizine göre, en fazla yan kök sayısı aynı istatistik gruba dahil olan, sirasi ile 1,5 cm, $3 \mathrm{~cm}, 6 \mathrm{~cm}$ ve $9 \mathrm{~cm}$ siklıkta yetişen fidanlarda (3,70 adet, 3,82 adet, 3,74 adet ve 3,03 adet) meydana gelmiştir. En düşük yan kök sayısı ise kontrol uygulamasında (1,88 adet) oluşmuştur.

\subsection{Farklı yetiștirme sıklığının diken ardıcının fidan taze ağırlığı (FTA) üzerine etkisi}

Araştırmada, farklı yetiştirme sıklığında yetişen diken ardıcı fidanları taze ağırlığı bakımından istatistiksel olarak $(\mathrm{p} \leq 0,05)$ farklılık göstermiştir. Yapılan Duncan çoklu karşılaştırma analizine göre üç gruba ayrılarak, en yüksek fidan taze ağırlığ 1 $3 \mathrm{~cm}$ sıklıkta yetişen fidanlarda $(5,15 \mathrm{~g})$ meydana gelmiştir. En düşük fidan taze ağırlığının ise kontrol uygulamasında olduğu $(2,26 \mathrm{~g})$ belirlenmiştir.

\subsection{Farklı yetiştirme sıklığının diken ardıcının gövde taze ağırlığı (GTA) üzerine etkisi}

Araştırma sonuçlarına göre, farklı yetiştirme sıklığında yetişen diken ardıcı fidanları gövde taze ağırlığı bakımından istatistiksel olarak $(p \leq 0,05)$ farklılık göstermiştir. Yapılan Duncan çoklu karşılaştırma analizine göre, en yüksek gövde taze ağır- 
Tablo 2. Diken ardıcı fidanların morfolojik özelliklerine ait varyans analizi

Table 2. Variance analysis results of prickly juniper seedlings morphological characteristics

\begin{tabular}{|c|c|c|c|c|c|}
\hline Morfolojik Özellikler & Varyasyon Kaynağ 1 & Kareler Toplamı & $\begin{array}{c}\text { Kareler } \\
\text { Ortalamas1 } \\
\end{array}$ & F Değeri & P Değeri \\
\hline \multirow{3}{*}{$\mathrm{FB}(\mathrm{cm})$} & Uygulama & 6,32 & 1,58 & \multirow{3}{*}{$0,60 \mathrm{~ns}$} & \multirow{3}{*}{0,67} \\
\hline & Hata & 39,24 & & & \\
\hline & Toplam & 45,55 & 2,62 & & \\
\hline \multirow{3}{*}{$\mathrm{KBÇ}(\mathrm{mm})$} & Uygulama & 3,29 & 0,82 & \multirow{3}{*}{$8,44^{*}$} & \multirow{3}{*}{0} \\
\hline & Hata & 1,46 & & & \\
\hline & Toplam & 4,76 & 0,09 & & \\
\hline \multirow{3}{*}{ YKS (adet) } & Uygulama & 10,77 & 2,69 & \multirow{3}{*}{$4,00^{*}$} & \multirow{3}{*}{0,02} \\
\hline & Hata & 10,09 & & & \\
\hline & Toplam & 20,86 & 0,67 & & \\
\hline \multirow{3}{*}{ FTA $(\mathrm{g})$} & Uygulama & 20,79 & 5,19 & \multirow{3}{*}{$11,21^{*}$} & \multirow{3}{*}{0} \\
\hline & Hata & 6,95 & & & \\
\hline & Toplam & 27,74 & 0,46 & & \\
\hline \multirow{3}{*}{ GTA $(g)$} & Uygulama & 7,52 & 1,88 & \multirow{3}{*}{$10,18^{*}$} & \multirow{3}{*}{0} \\
\hline & Hata & 2,77 & & & \\
\hline & Toplam & 10,29 & 0,18 & & \\
\hline \multirow{3}{*}{ KTA $(g)$} & Uygulama & 3,83 & 0,95 & \multirow{3}{*}{$3,98^{*}$} & \multirow{3}{*}{0,02} \\
\hline & Hata & 3,6 & & & \\
\hline & Toplam & 7,43 & 0,24 & & \\
\hline \multirow{3}{*}{ FKA $(g)$} & Uygulama & 4,74 & 1,18 & \multirow{3}{*}{$9,61^{*}$} & \multirow{3}{*}{0} \\
\hline & Hata & 1,84 & & & \\
\hline & Toplam & 6,58 & 0,12 & & \\
\hline \multirow{3}{*}{ GKA (g) } & Uygulama & 1,68 & 0,42 & \multirow{3}{*}{$10,64^{*}$} & \multirow{3}{*}{0} \\
\hline & Hata & 0,59 & & & \\
\hline & Toplam & 2,27 & 0,04 & & \\
\hline \multirow{3}{*}{ KKA (g) } & Uygulama & 1,06 & 0,26 & \multirow{3}{*}{$4,96^{*}$} & \\
\hline & Hata & 0,8 & & & 0,01 \\
\hline & Toplam & 1,87 & 0,05 & & \\
\hline & Uygulama & 0,01 & 0 & & \\
\hline KK (\%) & Hata & 0,02 & & $1,85 \mathrm{~ns}$ & 0,17 \\
\hline & Toplam & 0,04 & 0 & & \\
\hline & Uygulama & 1,07 & 0,26 & & \\
\hline K & Hata & 1,77 & & $2,28 \mathrm{~ns}$ & 0,11 \\
\hline & Toplam & 2,85 & 0,11 & & \\
\hline & Uygulama & 943,9 & 235,97 & & \\
\hline Gİ & Hata & 322,8 & & $10,97 *$ & 0 \\
\hline & Toplam & 1266,7 & 21,52 & & \\
\hline & Uygulama & 0,12 & 0,03 & & \\
\hline Kİ & Hata & 0,05 & & $9,71^{*}$ & 0 \\
\hline & Toplam & 0,16 & 0 & & \\
\hline
\end{tabular}

ns: önemsiz *p $\leq 0,05$

Tablo 3. Diken ardıcı fidanlarının morfolojik özelliklerinin yetiștirme sıklığına göre karşılaștırılması

Table 3. Comparison of morphological characteristics of prickly juniper seedlings according to cultivation density

\begin{tabular}{lcccccccccc}
\hline $\begin{array}{c}\text { Yetiştirme } \\
\text { S1klığ } 1\end{array}$ & $\begin{array}{c}\text { KBÇ } \\
(\mathrm{mm})\end{array}$ & $\begin{array}{c}\text { YKS } \\
(\mathrm{adet})\end{array}$ & $\begin{array}{c}\text { FTA } \\
(\mathrm{g})\end{array}$ & $\begin{array}{c}\text { GTA } \\
(\mathrm{g})\end{array}$ & $\begin{array}{c}\text { KTA } \\
(\mathrm{g})\end{array}$ & $\begin{array}{c}\text { FKA } \\
(\mathrm{g})\end{array}$ & $\begin{array}{c}\text { GKA } \\
(\mathrm{g})\end{array}$ & $\begin{array}{c}\text { KKA } \\
(\mathrm{g})\end{array}$ & GI & Kİ \\
\hline Kontrol & $1,93 \mathrm{~b}$ & $1,88 \mathrm{~b}$ & $2,26 \mathrm{c}$ & $1,38 \mathrm{~b}$ & $0,89 \mathrm{c}$ & $0,93 \mathrm{c}$ & $0,57 \mathrm{c}$ & $0,36 \mathrm{~b}$ & $59,23 \mathrm{a}$ & $0,12 \mathrm{c}$ \\
$1,5 \mathrm{~cm}$ & $2,79 \mathrm{a}$ & $3,70 \mathrm{a}$ & $3,72 \mathrm{~b}$ & $2,30 \mathrm{a}$ & $1,42 \mathrm{bc}$ & $1,63 \mathrm{~b}$ & $1,00 \mathrm{~b}$ & $0,62 \mathrm{~b}$ & $47,97 \mathrm{~b}$ & $0,20 \mathrm{bc}$ \\
$3 \mathrm{~cm}$ & $2,91 \mathrm{a}$ & $3,82 \mathrm{a}$ & $5,15 \mathrm{a}$ & $2,91 \mathrm{a}$ & $2,24 \mathrm{a}$ & $1,97 \mathrm{ab}$ & $1,27 \mathrm{ab}$ & $0,70 \mathrm{ab}$ & $43,06 \mathrm{bc}$ & $0,29 \mathrm{ab}$ \\
$6 \mathrm{~cm}$ & $2,94 \mathrm{a}$ & $3,74 \mathrm{a}$ & $4,70 \mathrm{ab}$ & $2,96 \mathrm{a}$ & $1,74 \mathrm{ab}$ & $2,37 \mathrm{a}$ & $1,28 \mathrm{ab}$ & $1,08 \mathrm{a}$ & $42,11 \mathrm{bc}$ & $0,34 \mathrm{a}$ \\
$9 \mathrm{~cm}$ & $3,06 \mathrm{a}$ & $3,03 \mathrm{a}$ & $4,54 \mathrm{ab}$ & $2,96 \mathrm{a}$ & $1,58 \mathrm{abc}$ & $2,03 \mathrm{ab}$ & $1,36 \mathrm{a}$ & $0,66 \mathrm{~b}$ & $40,13 \mathrm{c}$ & $0,29 \mathrm{ab}$ \\
\hline
\end{tabular}

*Her bir sütundaki aynı harflerle gösterilen ortalamalar arasında istatistiki açıdan bir fark yoktur $(\mathrm{p} \leq 0,05)$ 
lığ 1 aynı istatistik gruba ait olan, sırası ile 1,5 cm, 3 $\mathrm{cm}, 6 \mathrm{~cm}$ ve $9 \mathrm{~cm}$ sıklıkta yetişen fidanlarda $(2,30$ g, 2,91 g, 2,96 g ve 2,96 g) meydana gelmiştir. En düşük gövde taze ağırlığının ise kontrol uygulamasında olduğu (1,38 g) belirlenmiştir.

\subsection{Farklı yetiştirme sıklığının diken ardıcı kök taze ağırlığı (KTA) üzerine etkisi}

Farklı yetiştirme sıklığında yetişen diken ardıcı fidanları arasında kök taze ağırlığı bakımından istatistiksel olarak $(\mathrm{p} \leq 0,05)$ farklılık bulunmaktadır. Yapılan Duncan çoklu karşılaştırma analizine göre, en fazla kök taze ağırlığı $3 \mathrm{~cm}$ sıklıkta yetişen fidanlarda (2,24 g) meydana gelmiştir. En az kök taze ağırlığının ise kontrol uygulamasında olduğu $(0,89 \mathrm{~g})$ belirlenmiştir.

\subsection{Farklı yetiştirme sıklığının diken ardıcı fidan kuru ağırlığı (FKA) üzerine etkisi}

Farklı yetiştirme sıklığında yetişen diken ardıcı fidan kuru ağırlığı bakımından istatistiksel olarak $(\mathrm{p} \leq 0,05)$ farklılık bulunmaktadır. Yapılan Duncan çoklu karşılaştırma analizine göre üç gruba ayr1larak, en yüksek fidan kuru ağırlığı 6 cm sıklıkta yetişen fidanlarda $(2,37 \mathrm{~g})$ meydana gelmiştir. En düşük fidan kuru ağırlığının ise kontrol uygulamasında olduğu $(0,93 \mathrm{~g})$ tespit edilmiştir.

\subsection{Farklı yetiştirme sıklığının diken ardıcı gövde kuru ağırlığı (GKA) üzerine etkisi}

Farklı yetiştirme sıklığında yetişen diken ardıcı fidanları arasında gövde kuru ağırlığı bakımından istatistiksel olarak $(\mathrm{p} \leq 0,05)$ farklılık bulunmaktadır. Yapılan Duncan çoklu karşılaştırma analizine göre üç gruba ayrılarak, en yüksek gövde kuru ağırlığ $9 \mathrm{~cm}$ sıklıkta yetişen fidanlarda (1,36 g) oluşmuştur. En düşük gövde kuru ağırlığının ise kontrol uygulamasında olduğu $(0,57 \mathrm{~g})$ tespit edilmiştir.

\subsection{Farklı yetiștirme sıklığının diken ardıcı kök kuru ağırlığı (KKA) üzerine etkisi}

Farklı yetiştirme sıklığında yetişen diken ardıcı fidanları arasında kök kuru ağırlığ istatistiksel olarak $(\mathrm{p} \leq 0,05)$ farklılık bulunmaktadır (Tablo 2). Yapılan Duncan çoklu karşılaştırma analizine göre, en yüksek kök kuru ağırlığı $6 \mathrm{~cm}$ sıklıkta yetişen fidanlarda (1,08 g) oluşmuştur. En düşük kök kuru ağırlığının ise kontrol uygulamasında olduğu $(0,36 \mathrm{~g})$ tespit edilmiştir.

3.10. Farklı yetiştirme sıklığının diken ardıcı fidanlarının kuru kök yüzdesi üzerine etkisi

Farklı yetiştirme sıklığında yetişen diken ardıcı fidanları kuru kök yüzdesi bakımından farklılık göstermemektedir (Tablo 2). Ölçüm sonuçlarına göre, en yüksek kuru kök yüzdesi kontrol ve $6 \mathrm{~cm}$ (\%39) uygulamalarında, en düşük ise $9 \mathrm{~cm}(\% 33)$ yetiştirme sıklığında oluşmuştur.

\subsection{Farklı yetiştirme sıklığının diken ardıcı fidanlarının katlılık değeri üzerine etkisi}

Farklı yetiştirme sıklığında yetişen diken ardıcı fidanlarında katlılık değeri bakımından yapılan varyans analizi sonucunda istatistiksel anlamda önemli olmadığı belirlenmiştir (Tablo 2). Ölçüm sonuçlarına göre, en yüksek katlılık değeri $9 \mathrm{~cm}$ sıklıkta $(2,05)$, en düşük değerleri ise kontrol ve $1,5 \mathrm{~cm}$ sıklıkta $(1,59)$ yetişen fidanlarda olduğu belirlenmiştir.

\subsection{Farklı yetiştirme sıklığının diken ardıcı gürbüzlük indisi değeri üzerine etkisi}

Farklı yetiştirme sıklığında yetişen diken ardıcı fidanlarıarasındagürbüzlükindisideğeribakımından istatistiksel olarak $(\mathrm{p} \leq 0,05)$ farklılık bulunmaktadır (Tablo 3). Duncan çoklu karşılaştırma analizi sonuçlarına göre, en yüksek Gürbüzlük İndisi değeri kontrol uygulamasından $(59,23)$ elde edilen fidanlarda olduğu belirlenmiştir. Fidanlardaki en düşük Gürbüzlük İndisi aynı gruba dahil olan 3, 6 ve $9 \mathrm{~cm}$ sıklıkta yetişen fidanlarda sırası ile 43,06, 42,11 ve 40,13 değerlerinde olduğu tespit edilmiştir.

\subsection{Farklı yetiștirme sıklığının diken ardıcı fidanlarının kalite indeksi değeri üzerine etkisi}

Farklı yetiştirme sıklığında yetişen diken ardıcı fidanlarında kalite indeksi değeri bakımından istatistiksel olarak $\mathrm{p} \leq 0,05$ düzeyinde önemli farklılıklar bulunmaktadır (Tablo 3). Yapılan ölçüm sonuçlarına göre, en düşük kalite indeksi kontrol $(0,12)$ uygulamasında, en yüksek ise 3, 6 ve $9 \mathrm{~cm}$ siklıkta $(0,29,0,34$ ve 0,29$)$ yetişen fidanlarda olduğu belirlenmiştir.

\section{Tartışma ve Sonuç}

Ağaçlandırma çalışmalarında başarı için kullanılan fidanların kalitesi önemli olup, fidan kalitesi üzerinde de fidanlıkta uygulanmakta olan yetiştirme işlemleri hayati öneme sahiptir (Boydak ve Çalışkan, 2015; Alım ve ark., 2008). Fidan kalitesinin yüksek olmasındaki en önemli etkenlerden biri yetiştirme sıklığıdır. Ekim yastıklarında yetiştirilen fidanlar arasındaki mesafe, fidanın çap ve boy gibi morfolojik özellikleriyle, fizyolojik özellikleri üzerinde belirleyici olmaktadır. Bu durumun bir sonucudur ki, sık şekilde yetiştirilmiş boylu ve ince gövdeli fidanlar iyi yetişme ortamlarında bile 
dikim şokuna uğrayabilmektedir (Ürgenç, 1998). Tolay (1987) morfolojik yapı itibariyle kaliteli bir fidanı, belirli bir minimum çapa, yoğun köklenmiş bir kök yapısına, kök ile dengeli bir yapıda ve fazla boylu olmayan iyi dallanmış bir gövde yapısına sahip fidan olarak tanımlamaktadır.

Fidan kalitesinin tespitinde fidanların morfolojik ve fizyolojik özellikleri kullanılmakta olup, bu amaçla genel olarak kullanılan morfolojik özellikler fidan boyu ve ağırlığ çap1, kök rengi, gövde-kök oranı ve gürbüzlük indisidir (Ritchie, 1984). Dirik (1993) ise fidan kalitesi belirlemede en önemli parametrelerden biri olarak fidan boyunu işaret etmekte olup, Coşgun ve ark. (2008) ve Semerci (2002) de yapmış oldukları çalı̧̧malarda fidan boyunun kalite göstergesi olarak kullanılması gerektiğine vurgu yapmışlardır.

Yapmış olduğumuz çalışma sonucunda, diken ardıcı fidanlarında uygulanan farklı yetiştirme sıklığının fidan boyu gelişimi üzerinde etkili olmadığı sonucuna ulaşılmıştır. Çalışma sonuçlarına benzer sonuçlara Keskin (1992) tarafından kızılçam fidanları üzerine ve Alım ve ark. (2008) tarafından badem fidanları üzerine yapılan çalışmalarda da ulaşılmış ve yetiştirme sıklığının fidan boyu gelişimi üzerinde bir farklılık yaratmadığı belirtilmiştir. Aynı şekilde yetiştirme sıklığının doğu ladini fidanları gelișimi üzerindeki etkileri bağlamında gerçekleştirilen bir çalışmada, yetiştirme sıklığının kök boğazı çapını ve fidan ağırlığını etkilediği, fidan boyunu ise etkilemediği tespit edilmiştir (Eyüpoğlu, 1988). Fidan boyu üzerinde yetiştirme sıklığının bir etkisinin bulunmadığına yönelik bulgulara kızılağaçta Eyüpoğlu (1975) ve Quercus alba'da Wichman ve Coggeshal (1984) tarafindan da ulaşılmıştır. Nitekim Duryea (1984), düşük ekim sıklığında yetişen fidanların genel olarak daha çaplı, kök ve gövde kuru ağırlıklarının daha fazla olduğunu, fidan boyu ile kök-gövde oranının ise her zaman yetiştirme sıklığından etkilenmediğini belirtmektedir. Ayrıca, yetiștirme sıklığının fidan boyu üzerinde etkili olduğunu ortaya koyan çalışmalar da bulunmakta olup, Deligöz (2012), Acer negundo fidanları üzerinde, Özübek ve Deligöz (2016), kokulu ardıç fidanları üzerinde yaptıkları çalışmalarda yetiştirme sıklığının fidan boyu üzerinde etkili olduğunu tespit etmişlerdir.

Öte yandan fidan kalitesi belirlemelerinde kök boğazı çapının fidan boyundan daha önemli bir parametre olduğu, kalın çaplı ve boylu fidanların daha fazla yaprak ve ibreye sahip olmalarından dolayı daha yüksek besin maddesi içeriğine sahip oldukları savunulmaktadır (Yahyaoğlu ve Genç, 2007). Cleary ve Greaves (1979), kök boğazı çapının fidanın dayanıklılı̆̆ını gösteren önemli bir parametre olduğuna vurgu yapmaktadır. Yapmış olduğumuz çalışma sonucunda ise diken ardıcında fidan sıklığının kök boğazı çapını etkilediği, sıklık uygulaması yapılmayan fidanlar (kontrol) ile karşılaştırıldığında en iyi çap gelişiminin $9 \mathrm{~cm}$ sıklıkta yetişen fidanlarda olduğu ve dört farklı yetiştirme sıklığında yetişen fidanlar arasındaki farklılıkların önemsiz olduğu belirlenmiştir.

Benzer kapsamda yapılan çalışma sonuçları incelendiğinde, genel olarak yetiştirme sıklığ fazlalaştıkça fidan kök boğazı çapının azaldığı, azaldıkça da fidan kök boğazı çapının arttığı görülmektedir (Özdemir, 1971). Nitekim Alım ve ark. (2008) tarafindan badem fidanları üzerinde, Cengiz ve Şahin (2002) tarafindan yalancı akasya ve kokar ağaç türlerinde, Deligöz (2012) tarafından Acer negundo da, Özgübek ve Deligöz (20169 tarafından kokulu ardıç'ta ve Schultz ve Thompson (1997) tarafından ceviz ve kırmızı amerikan meşesinde gerçekleştirilen çalışmalarda yetiştirme sıklığının kök boğazı çapını etkilediği ve sıklık azaldıkça çapın arttığı sonucuna ulaşılmıştır.

Fidan kök boğazı çapının ağaçlandırma çalışmalarının başarısı açısından önemli olduğu birçok çalışmayla ortaya konmuş bulunmaktadır. Nitekim yapılan bir çalışmada $1+0$ kokulu ardıç fidanının kök boğazı çapının 1,9 mm'den, boz ardıç fidanının kök boğazının ise 1,5 mm'den daha kalın olmasının fidan tutma başarısını \%80'nin üzerine çıkardığ 1 tespit edilmiştir (Gültekin ve ark., 2005). Karaçam için Kızmaz (1993) tarafından yapılan bir çalışmada ise Isparta ve benzeri bölgelerde kök boğazı çapının 3,5 mm ve fidan boyunun ise $6,1 \mathrm{~cm}$ 'den fazla olması gerektiği, Bolu ve benzeri bölgelerde bu değerlerin sirasiyla 3,0 mm ve 5,1 cm'den fazla olması gerektiği belirtilmiştir. Genç ve ark. (1999) ise ağaçlandırmalarda kullanılacak karaçam fidanlarının kök boğazı çapı ve boyunun sırasıyla $3 \mathrm{~mm}$ ve $5 \mathrm{~cm}$ 'den fazla olması gerektiğini belirtmiştir.

Fidan kalitesinin belirlenmesindeki kriterlerden olan, 5 cm'den daha uzun yan kök sayısı incelendiğinde, farklı yetiştirme sıklığında yetişen fidanların sıklık uygulaması yapılmayan (kontrol) fidanlara göre daha fazla yan kök oluşturduğu belirlenmiştir. Araştırma bulgularımızla benzer bir şekilde Keskin (1992)'in kızılçam fidanları üzerinde yaptığ 1 bir çalışmada, fidan sıklığının 5 cm'den uzun yan kök sayısını etkilediği, ekim sıklığı azaldıkça yan kök sayısında artış olduğu, en iyi sonucun 6 ve 9 cm'lik 
sıklıklarda meydana geldiği bildirilmiştir. Ayrıca Alım ve ark. (2008) tarafından yapılan çalışmada, farklı ekim sıklığında yetişen badem fidanlarında 5 cm'den uzun yan kök sayısı ekim sıklığından en çok etkilenen fidan özelliklerinden olmuştur.

Fidan kalitesinin belirlenmesinde fidan boyu ve kök boğazı çapı yanında diğer morfolojik özellikler de oldukça önem taşımaktadır. Bu araştırmada en uygun yetiştirme sıklığının tespit edilebilmesi amacı ile FTA, GTA, KTA, FKA, GKA ve KKA gibi morfolojik özellikler de belirlenmiştir. $\mathrm{Bu}$ morfolojik özelliklerden FTA, GTA ve KTA için en iyi gelişimi $3 \mathrm{~cm}$ yetiştirme sıklığında, FKA, GKA ve KKA için ise $6 \mathrm{~cm}$ yetiştirme sıklığında yetişen fidanlarda elde edilmiştir. En düşük gelişimler ise herhangi bir uygulama yapılmayan kontrol işleminde gerçekleşmiştir. Yetiştirme sıklığ1nın fidan, gövde ve kök kuru ağılıkları üzerinde etkili olduğuna dair benzer sonuçlara Özübek ve Deligöz (2016) tarafından kokulu ardıç’ta yapılan çalışmada da ulaşılmıştır. doğu ladini fidanlar1 ile yapılan bir çalışmada da (Eyüpoğlu, 1988) benzer sonuçlara ulaşılmış, fidan sıklığının, fidan ağırlığını arttırdığ1 tespit edilmiştir. Aynı şekilde Keskin (1992) tarafından kızılçamda fidan sıklığının fidan kuru ağırlığını etkilediği, kökgövde oranını ise etkilemediği tespit edilmiştir. Benzer sonuçlara yalancı akasya (Cengiz ve Şahin 2002; Semerci ve ark., 2008), kokar ağaç (Cengiz ve Şahin 2002), dişbudak (Çiçek vd., 2007) ve kuş iğdesi (Gülcü ve Çelik Uysal, 2010) türlerinde yapılan çalışmalarda da ulaşılmıştır.

FTA ve KTA açısından $3 \mathrm{~cm}$ yetiştirme sıklığında yetişen fidanlar 6 ve $9 \mathrm{~cm}$ sıklıkta yetişen fidanlara oranla daha yüksek değerlere sahipken, kuru ağırlıklar itibariyle $3 \mathrm{~cm}$ sıklıkta yetişen fidanların daha düşük değerlere sahip oldukları görülmektedir. Bu durumun, işlem grupları arasındaki fidanların farklı nem içeriğine sahip olmalarından kaynaklandığı düşünülmektedir.

Fidan kalite sınıflandırmalarında kullanılan bir başka kriter de kuru kök yüzdesidir ve genel olarak bu değerin yüksek olması istenir. Ancak Genç (1992), yüksek değerlerin fidan boyu ve katlılık özelliklerinin olumsuzluğundan da kaynaklanabileceğini, bu durumda ise kuru kök yüzdesi değerinin fidan kalite ölçütü olarak kullanılmasının yanıltıcı olabileceğine işaret etmektedir. Bizim çalışmamızda, farklı ekim sıklığında yetiştirilen fidanların kuru kök yüzdesi bakımından farklılık göstermediği, işlemler kıyaslandığında kök yüzdesinin \%33 ile \%39 arasında değiştiği tespit edilmiştir
Fidanların toprak üstü ve toprak altı organları arasındaki dengeyi belirten katlılık değeri de (gövde-kök oranı) fidan kalite sinıflandırmalarında kullanılmaktadır. Genç (1992) bu oranın düşük olması durumunda fidanın topraktaki su ve besin maddelerinden daha fazla yararlanabileceğini, özellikle kurak ortamlarda toprak üstü kısımlarından transpirasyonla oluşacak su kaybının az olacağını belirtmekte ve gövde-kök oranı 2 ve 3 olan fidanların kurak yetişme ortamlarında daha başarılı olduğuna vurgu yapmaktadır. Cleary ve Greaves (1979) ise bu oranın 3 ve üzerinde olmasının özellikle kurak ve yarı-kurak bölgeler için bir sorun olduğunu, bu bölgelerde yapılacak çalışmalarda katlılık değerinin 3'ten fazla olmaması gerektiğini bildirmektedir. Tür özelinde bakıldığında da benzer rakamların değişik türler için tavsiye edildiği görülmektedir (Eyüpoğlu, 1988; Turna, 2002; Mullin ve Chritl, 1981). Yaptığımız araştırma sonuçlarına göre ise fidanlara uygulanan farklı yetiştirme sıklığının katlılık üzerinde etkili olmadığı tespit edilmiştir. Yapılan uygulamaların tümünde fidanların katlılık değerleri belirtilen ideal aralıklar içerisinde yer almıştır.

Fidan kalite sınıflamasında kullanılan başka bir kriter de Gürbüzlük İndisidir ve fidan boyunun kök boğazı çapına oranını ifade eder (Aldhous 1994). Bu değerin küçük olması fidanların kalitesi açısından istenen bir özellik olup, düşük Gürbüzlük İndisine sahip fidanlar dikim ve taşıma zararlarından daha az etkilenmekte ve dikim başarısı daha yüksek olmaktadır (Genç, 1992). Çalışmamız kapsamında, yetiştirme sıklığının Gürbüzlük İndisini etkilediği tespit edilmiştir. S1klık uygulaması yapılmayan fidanlar ile karşılaştırıldığında en düşük Gürbüzlük İndisi 3, 6 ve $9 \mathrm{~cm}$ sıklıkta yetişen fidanlardan elde edilmiştir. Ayrıca en yüksek Gürbüzlük İndisi değerinin kontrol uygulamasında olduğu belirlenmiştir. Gürbüzlük indisi sınıflamasına göre Gİ değeri 50'nin altında olan fidanlar iyi fidan, 50 - 60 arası olan fidanlar orta fidan ve 60 üstünde olan fidanlar ise kötü fidan olarak kabul edilmektedir (Yahyaoğlu ve Genç, 2007). Çalışmamızda elde edilen değerler incelendiğinde, kontrol dışındaki tüm sıklık uygulamalarından elde edilen fidanların "iyi fidan” sınıfına girdiği belirlenmiştir Çalışma sonuçlarımıza benzer olarak, Özübek ve Deligöz (2016)'ün Kokulu Ardıç’ta yapmış oldukları çalışmada da, yetiştirme sıklığının Gürbüzlük İndisi üzerinde etkili olduğu sonucuna ulaşılmıştır.

Fidan kalite indeksi 1' e yakın ve daha yüksek bulunan fidanlar yüksek kaliteli olarak kabul edilmektedir (Dickson ve ark. 1960; Aslan, 1986). 
Fidan kalite indeksi Dickson ve ark. (1960) tarafından geliştirilmiştir ve morfolojik ölçütlerin çoğunu içermektedir. Bu kapsamda yapılan incelemede, yetiştirme sıklığının fidan kalite indeksi üzerinde etkili olduğu tespit edilmiştir. Kalite indeksi bak1mindan aralarında farklılık olmayan 3, 6 ve $9 \mathrm{~cm}$ sıklıkta yetişen fidanlar en iyi sonucu vermiştir. Kontrol işlemine ait fidanlar en son sırada yer almıştır. Kalite indeksi üzerinde yetiştirme sıklığ1nın etkili olduğuna dair benzer sonuçlara kokulu ardıç türü için Özübek ve Deligöz (2016) tarafından da ulaşılmıştır.

Çalışma sonuçları genel olarak değerlendirildiğinde, diken ardıcı fidanlarının morfolojik özellikleri üzerine yetiştirme sıklığının önemli etkilerinin olduğu görülmektedir. Ekim yastıklarında yetiştirme sıklığı azaldıkça daha kalın çaplı, gövde taze ve kuru ağırlığı daha fazla ve daha çok yan kök sayısına sahip olan fidanlar elde edilmiştir. Fidanlar arasında kök boğazı çapı ve yan kök sayısı bakımından en yüksek değerler ekim sıklığı uygulanmayan kontrol dışındaki işlemlerin tamamında, fidan ağırlıkları bakımından ise $3 \mathrm{~cm}$ ekim sıklığ uygulamasında yetişen fidanlarda elde edilmiştir. Gürbüzlük indisi ve kalite indeksi açısından değerlendirildiğinde ise 3, 6 ve $9 \mathrm{~cm}$ ekim sıklığında yetişen fidanların öne çıktığı görülmektedir.

Bu kapsamda elde edilen bütün bulgular ve birim alandan elde edilen fidan miktarı açısından değerlendirildiğinde Eğirdir Orman Fidanlığı koşullarında $3 \mathrm{~cm}$ ekim sıklığı uygulanmasının kaliteli fidan üretimi için uygun olacağı düşünülmektedir.

\section{Teşekkür}

Bu makale; Orman Genel Müdürlüğü, Batı Akdeniz Ormancılık Araştırma Enstitüsü Müdürlüğünce yürütülen 'Eğirdir Orman Fidanlığı'nda Diken Ardic1 (Juniperus oxycedrus L. subsp. oxycedrus) Fidan Yetiştirme Sıklığının Fidan Morfolojisine Etkileri” isimli ve 19.1210/2009-2014-2016 no'lu Araştırma Projesi kapsamında hazırlanmıştır.

\section{Kaynaklar}

Akkemik, Ü., Yaltırık, F. 2011. Türkiye'nin Doğal Gymnospermleri (Açık Tohumlular). Orman Genel Müdürlügü Yayını, 214s. Ankara.

Alım, E., Şahin, M., Gültekin, H.C., 2008 Ekim sıkl1ğının badem (Prunus amygdalus L.) fidanlarının morfolojik özelliklerine etkileri, Batı Akdeniz Ormancılık Araştırma Müdürlüğü Dergisi, Sayı: 9, Antalya.

Aldhous, J.R. 1994. Nursery policy and planning. In:
Aldhous, J. R. and Mason, W. L. (Eds) Forest nursery practice. British Forestry Comm. Bull. No. 111, pp. 1-12. HMSO, London.

Anonim, 2015. Orman Varlığımız, Orman Genel Müdürlüğü Yayını, Ankara.

Boydak, M., Çalışkan, S. 2015. Ağaçlandırma. OGEMVAK Yayın1, 712 s. Ankara.

Cengiz, Y., Şahin, M., 2002. Bazı yapraklı ağaç fidanlarının yetiştirilmesinde ekim sıklığın büyüme üzerine etkileri, Batı Akdeniz Ormancılık Araştırma Enstitüsü Dergisi. Say1: 4: 123-136 s.

Chavasse, C.G.R. 1980. Planting stock quality: a review of factors affecting performance. The New Zealand Journal of Forestry, 25: 145-171.

Cleary, B.D., Greaves, R.R. 1979. Fidan. Ormancilı Araştırma Enstitüsü Dergisi, Cilt: 25, Sayı: 2, 31-67, Ankara (Çeviren: Eyüboğlu, A.K.).

Coşgun, S., Şahin, M., Özkurt, N., Parlak, S., 2008. Kızılçam (Pinus brutia Ten.) fidanlarında kalite sınıflarının belirlenmesi, çevre ve orman bakanlığı, Batı Akdeniz Ormancılık Araştırma Müdürlüğü, Teknik Bülten No: 29, Antalya, 67s.

Çatal, A.Y., 2002. Toros sediri (Cedrus libani A. Rich.)'nde yetiştirme sıklığının bazı morfolojik fidan özelliklerine etkisi, Süleyman Demirel Üniversitesi, Fen Bilimleri Enstitüsü, Yüksek Lisans Tezi, Isparta, $83 \mathrm{~s}$.

Çiçek, E., Çiçek N., Bilir, N., 2007. Effects of seedbed density on one-year old Fraxinus agustifolia seedling characteristics and out planting performance. New Forests, 33:81- $91 \mathrm{p}$.

Deligöz, A., 2012. Ekim sıklığının Acer negundo L. fidanlarının morfolojik ve fizyolojik özellikleri üzerine etkisi. Bartın Orman Fakültesi Dergisi, Cilt: 14, Sayı: 21.

Dickson, A., Leaf A.L., Hosner, F., 1960. Quality appraisal of white spruce and white pine seedling stock in nurseries, Forestry Chronicle, 36, p: 10-13.

Dirik, H., 1993. Kızılçam (Pinus brutia Ten.)'da bazı önemli fidan karakteristikleri ile dikim başarısı arasındaki ilişkiler, İ.Ü. Orman Fakültesi Dergisi, Seri: A, Cilt: 43, Say1: 2, s: 51-57, İstanbul.

Duryea, M. L., 1984. Nursery cultural practices, impacts on seedling quality, forest nursery manual production of bareroot seedlings, Duryea, State Universty, p. 146-149, 153-158, 160-161.

Eler, Ü., 1988. Türkiye'deki boylu ardıç (Juniperus excelsa Bieb.) ormanlarında hasılat araştırmaları, Ormancılık Araştırma Enstitüsü Yayınları, Teknik Bülten No: 192.

Eler, Ü., 2002. Ardıcın doğal gençleştirilmesi. Batı Ak- 
deniz Ormancılık Araştırma Müdürlüğü Yayınları, Sayı 4, s. 109-122.

Eler, Ü., Keskin, S. 1990. Korumaya alınan tahribat görmüş genç boylu ardıç (Juniperus excelsa Bieb.) ve kokulu ardıçların (Juniperus foetidissima Willd.) gelişme durumları. Ormancılık Araştırma Enstitüsü Dergisi, 36(72): 7-18.

Eler, Ü., Çetin, A., 2006. Ardıç Tohumunun Çimlendirme Olanaklar1. Süleyman Demirel Üniversitesi Orman Fakültesi Dergisi, Seri A, Say1 1, s. 33-45.

Eler, Ü., Keskin, S., Örtel, E., 1990. Toros sediri (Cedrus libani A. Rich.) fidanlarında kalite sınıflarının belirlenmesi, Ormancılık Araştırma Enstitüsü Yayınları, Teknik Bülten Serisi No: 240

Eliçin, G., 1977. Türkiye Doğal Ardıç (Juniperus L.) taksonlarının Yayılışları ile Önemli Morfolojik ve Anatomik Özellikleri Üzerine Araştırmalar. İÜ. Orman Fakültesi Yayını No: 2327/232, 109 s.

Eyüpoğlu, A.K., 1975. Kızılağacın (Alnus barbata) Fidanlıkta Yetiştirilmesinde Uygun Ekim Sıklığının Saptanması. Ormancılık Araştırma Enstitüsü Yayınları, Teknik Bülten No: 74.

Eyüpoğlu, A.K., 1988. Fidanlıkta değişik sıklık derecelerinde yetiştirilmiş şaşırtılmış ve şaşırtılmamış Doğu ladini (Picea orientalis (L.) Link) Fidanlarının arazideki durumları. Ormancılık Araştırma Enstitüsü Yayınları, Teknik Bülten No: 201.

Genç, M., 1992. Doğu Ladini (Picea orientalis (L.) Link) Fidanlarına Ait Bazı Morfolojik ve Fizyolojik Özelliklerle Dikim Başarısı Arasındaki İlişkiler, (Doktora Tezi), KTÜ. Fen Bilimleri Enstitüsü.

Genç, M., Güner, Ș.T., Şahan, A., 1999. Eskișehir, Eğirdir ve Seydişehir Orman Fidanlıklarında 2+0 Karaçam Fidanlarında Morfolojik İncelemeler. Turkish Journal of Agriculture \& Forestry, 23 (Ek Say1 2) 517-525.

Gülcü, S., Gültekin, H.C., 2005a. Değişik Yetiștirme Ortamlarının Boylu Ardıç'ın (Juniperus excelsa Bieb.) Bazı Morfolojik Fidan Kalite Kriterlerine Olan Etkileri, Batı Akdeniz Ormancılık Araştırma Enstitüsü Yayınlar1, No: 283/31, say1: 6, s: 1-16.

Gülcü, S., Gültekin, H.C., 2005b. Boylu Ardıç (Juniperus excelca Bieb.) ve Küçük Kozalaklı Katran Ard1c1'nda (Juniperus oxycedrus L.) Uygun Ekim Yöntemlerinin Belirlenmesi. Süleyman Demirel Üniversitesi Orman Fakültesi Dergisi, Seri: A, Sayı: 1, s.: 37-48.

Gülcü, S., Çelik Uysal, S., 2010. Kuș İğdesinde (Elaeagnus angustifolia L.) Yetiştirme Sıklığının Fidan Morfolojik Özelliklerine Etkisi. Süleyman Demirel Üniversitesi Orman Fakültesi Dergisi, Seri: A, Say1: 2, Y11: 2010, s. $74-81$.

Gülcü, S., Gültekin, H.C., Gürlevik, N., 2005. Göller
Yöresi Ardıç (Juniperus ssp.) Ormanlarının Sorunları ve Rehabilitasyonu. Korunan Doğal Alanlar Sempozyumu Sözlü Bildiriler Kitab1, s. 561-567.

Güler, S. 2000. Doğu Anadolu Bölgesinde Yayılış Gösteren Ardıç (Juniperus L.) Taksonları ve Suni Yoldan Üretilme Olanakları. Doğu Anadolu Ormancılık Araştırma Müdürlügü Yayını Müdürlük Yayın No: 9, s.: 12.27.

Gültekin, H.C., 2007. Türkiye Ardıç (Juniperus L.) Türlerinin Ekolojisi ve Silvikültür Teknikleri, TMMOB Orman Mühendisleri Odası, Yayın No: 27.

Gültekin, H.C., Öztürk, H., 2002. Boylu Ardıç, Kokulu Ardıç ve Katran Ardıcının Doğal Gençlikleri Üzerine Gözlemler, Fidanlık Tekniği Hakkında Deneyimler. Orman Mühendisliği Dergisi, Say1: 9-10, s.: 5-9.

Gültekin, H.C., Gültekin, Ü.G., 2003. Boylu Ardıç (J. Excelsa Bieb.), Kokulu Ardıç (J. Foetidissima Willd.), Diken Ardic1 (J. oxycedrusL. Subsp. oxycedrus) Tohum Niteliklerinin Geliştirilmesi ve Tohumlarının Değişik Katlama Yöntemleri İle Çimlendirilmesi, Orman ve Av Dergisi, Sayı: 2

Gültekin, H.C., Gültekin, Ü.G,. 2005. Bazı Ardıç Türlerinde Tohum Ekimi Yöntemi İle Doğal Gençleştirme Çalışması, Orman Mühendisliği Dergisi, Sayı 2, Ankara.

Gültekin, H.C., Divrik, A., Gültekin, Ü.G., 2004. Boz Ardıç (Juniperus excelsa bieb.), Kokulu Ardıç (Juniperus foetidissima Wild.), Diken Ardıç (Juniperus oxycedrus L. Subsp. oxycedrus), Servi Ardıç (Juniperus phoenicea L.), Andiz (Arceuthos drupacea Ant. Et. Cotschy.) Fidan Özellikleri, Orman Mühendisliği Dergisi, No: 2 , Ankara.

Gültekin, H.C., Gülcü, S., Gültekin, Ü.G., DİRİK, A., 2003. Boylu Ardıç (Juniperus excelsa Bieb.) Tohumlarına Ekimden Önce Uygulanabilecek Bazı Basit Sınıflandırma Yöntemlerinin Çimlenmeye Olan Etkilerinin Belirlenmesi Üzerine Araștırmalar. Kafkas Üniversitesi Artvin Orman Fakültesi Dergisi, Cilt: 4, Sayı: 1-2, s.: 111-121.

Gültekin, H. C., Cetin, M.E., Datumani, A., Ateș, M., Altınsoy, S., Divrik, A., Gültekin, Ü.G., Yiğci, M., Divrik, H., Sarıl1, Z., 2005. Göller Bölgesi Ardıç (Juniperus L.) Ağaçlandırma ve Yapay Gençleştirme Çalışmaları Hakkında Bazı Tespitler. Batı Akdeniz Ormancılık Araştırma Enstitüsü Yayınları, No: 283/31, say1: 6, s.: 43-62.

Kalıpsız, A., 1981. İstatistik Yöntemler. İ.Ü. Orman Fak. Yay. 2837/294, 558 s., İstanbul.

Keskin, S., 1991. Kokulu Ardıç (Juniperus foetidissima Willd.) ve Boylu Ardıç (Juniperus excelsa Bieb.)'ın Çelikle Üretilmesi Olanakları Üzerine Araștırmalar. Ormancılık Araştırma Enstitüsü Yayınları, Teknik Bülten Serisi No: 233, s.: 1-30.

Keskin, S., 1992. Kızılçamda (Pinus brutia Ten.) Fidan Sıklığının Önemli Morfolojik Özellikler Üzerine Etki- 
leri, Ormancılık Araştırma Enstitüsü Yayınları Teknik Bülten No: 227, Ankara.

Kızmaz, M., 1993. Karaçam Fidanlarının Kalite Sınıflarının Belirlenmesi Üzerine Araştırmalar, Ormancılık Araştırma Enstitüsü Yayınları, Teknik Bülten Serisi, No: 238.

Mullin, R.E., Chritl, C., 1981. Morphological Grading of WhiteSpruceNursery Stocks, For.Chorn, 57,3,p: 126-130.

Örtel, E. 2016. Boylu Ardıç’ın (Juniperus excelsa Bieb.) yapay gençleştirilmesi. Batı Akdeniz Ormancılık Araştırma Enstitüsü Projesi, 33 s., Antalya.

Özdemir, Ö.L., 1971. Karaçam (Pinus nigra Arnold.)'1n Fidanlıklarda Yetiştirilme Tekniği Üzerine Bazı Denemeler. Ormancılık Araştırma Enstitüsü Yayınları, Teknik Bülten Serisi No. 49, 51 s., Ankara.

Özpay, Z., Coşkun, S., Terzi, M., 1999. İki Yaşlı Karaçam ve Sarıçam Fidan Eldesinde Farklı Tekniklerin Fidan Gelişimi Üzerine Etkileri, 1. International Symposium on Protection of Natural Environment and Ehrami Karaçam, Kütahya.

Özübek, Ş.D., Deligöz, A. 2016. Kokulu Ardıç (Juniperus foetidissima Wild.) Fidanlarının Morfolojisi, kök gelişme potansieli ve karbonhidrat içeriği üzerinde yetiştirme sıklığının etkileri. Süleyman Demirel Üniversitesi Fen Bilimleri Enstitüsü Dergisi, 20(2): 369-375.

Pamay, B., 1955. Türkiye Ardıç (Juniperus L.) Türleri ve Yayılışları. İstanbul Üniversitesi Orman Fakültesi Dergisi, Cilt: 5, Say1: 1-2, s. 91-120.

Ritchie, G.A., 1984. Assessing Seedling Quality, Forest Nursery, In: Production of Bareroot Seedlings, Duryea, M.L. and Landis, T.D. (eds.), Martinus Nijhoff / Dr.W. Junk Publishers, The Hague / Boston / Lancester For Research Laboratory, Oregon StateUniversity, Corvallis, pp. $243-259$.

Saatçioğlu,F., 1976.FidanlıkTekniği.İstanbulÜniversitesi Orman Fakültesi Yayınları. Yayın No: 223. İstanbul.

Schultz, R.C., Thompson, J.R., 1997. Effect of Density Control and Undercutting on Root Morphology of $1+0$ Bareroot Hardwood Seedlings: Five-year Field Performance of Root-graded Stock in the Central USA. New Forests 13: 301-314.

Semerci, A., 2002. Sedir (Cedrus libani A. Rich.) Fidanlarına Ait Bazı Morfolojik ve Fizyolojik Karakteristikler ile İç Anadolu'daki Dikim Başarısı Arasındaki İlişkiler.
İç Anadolu Ormancılık Araştırma Müdürlüğü, Teknik Bülten No: 279, Ankara, 142s.

Semerci, A., Güner, Ş., T., Çömez, A., Çelik, N., Karataş, R., Koray, E., Genç, M., Tuncer, E., Güner, D., 2008. Yetiştirme Sıklığının Yalancı Akasya (Robinia pseudoacacia L.) Fidanlarının Bazı Morfolojik ve Fizyolojik Özellikleri İle Dikim Başarısına Etkileri: Eskişehir Fidanlığı Örneği, İç Anadolu Ormancılık Araştırma Enstitüsü Yayınları, Teknik Bülten No: 285.

Şahin, M. E., 1985. Bazı Ardıç Türlerinin Çelikle Üretim İmkanları Üzerinde Bir Gözlem. Orman Mühendisliği Dergisi, Say1 5, s. 49-51.

Şimşek, Y., 1992. Kaliteli Kayın (Fagus orientalis Lipsky) Fidanı Yetiştirme Tekniği Araştırma Sonuçları, Ormancılık Araştırma Enstitüsü Yayınları, Teknik Rapor Serisi No: 56.

Tetik, M., 1995. Sarıkamış Fidanlığında Ekim Sıklığ1nın Sarıçam (Pinus silvestris L.) Fidanlarının Kalitesine ve Dikimdeki Başarısına Etkileri, Ormancılık Araștırma Enstitüsü Yayınları, Teknik Bülten No. 244, Ankara.

Tolay,U., 1987. Yapraklı TürOrman Ağaçları FidanlıkTekniği. Kavak ve Hızlı Gelişen Yabancı Tür Orman Ağaçları Araştırma Enstitüsü, Teknik Bülten No: 140, İzmit.

Tosun, S., Özpay, Z., Tetik, M., 1991. Sarıçam (Pinus sylvestris L.) Fidanlarının Kalite Sınıflarının Belirlenmesi Üzerine Araştırmalar. Ormancılık Araştırma Enstitüsü Yayınları, Teknik Bülten Serisi No. 239.

Turna, İ., 2002. Fidan Standardizasyonu, Yayınlanmamış Ders Notları, K.T.Ü., Orman Fakültesi, Orman Mühendisliği, Trabzon.

Ürgenç, S., 1998. Genel Plantasyon ve Ağaçlandırma Tekniği, İstanbul Üniversitesi Orman Fakültesi Yayınlar1, No: 3997/444, İstanbul, $664 \mathrm{~s}$.

Yahyaoğlu, Z., Genç, M., 2007. Fidan Standardizasyonu, Süleyman Demirel Üniversitesi, Orman Fakültesi, Yayı1n No.75, Isparta.

Yaltırık, F., 1988. Dendroloji Ders Kitabı I Gymnospermae (Açık Tohumlular), İstanbul Üniversitesi Orman Fakültesi Yayını No. 3443/386, 320 s.

Wichman, J.R., Coggeshall, M.V., 1984. Effects of Seedbed Density and Fertilization on Root-pruned 2-0 White Oak Nursery Stock. Tree Planters' Notes 35(4):22-24. 